Research Paper:

\title{
Chronic Administration of Donepezil in Inhibitory and Spatial Learning and Memory in Male Rats
}

\author{
Nasrin Hashemi-Firouzi ${ }^{1}$, Ali Ghaleiha ${ }^{2}$, Alireza Komaki ${ }^{1},{ }^{*}$ Siamak Shahidi ${ }^{1}$
}

1. Neurophysiology Research Center, Hamadan University of Medical Sciences, Hamadan, Iran.

2. Research Center for Behavioral Disorders and Substance Abuse, Hamadan University of Medical Sciences, Hamadan, Iran.

$\begin{aligned} & \text { Use yourdevice toscan } \\ & \text { and read the artice online }\end{aligned}$
ditation Hashemi-Firouzi N, Ghaleiha A, Komaki AR, Shahidi S. Chronic Administration of Donepezil in Inhibitory and Spa-
tial Learning and Memory in Male Rats. Avicenna J of Neuropsychophysiology. 2019; 6(1):11-18. http://dx.doi.org/10.32598/
ajnpp.4.3.310

\section{(c) 0 (3)}

Article info:

Received: 10 Sep 2018

Accepted: 27 Dec 2018

Available Online: $01 \mathrm{Feb} 2019$

Keywords:

Donepezil, Learning,

Memory, Rat

\section{A B STRACT}

Background: Cholinergic dysfunction is involved with age-related cognitive deficits and Alzheimer's disease. Donepezil is a reversible acetylcholinesterase inhibitor.

Objectives: The present study examined the ability of chronic supplementation with donepezil on the cognition of the healthy young rats.

Materials and Methods: Twenty young male Wistar rats (140-160 g) were divided into the control and experimental groups. The rats received the oral administration of saline or $0.3 \mathrm{mg} / \mathrm{kg}$ of donepezil for 30 consecutive days. Then, they were trained and tested with Inhibitory Avoidance (IA) and 8-Radial Arm Maze (RAM) tasks.

Results: There was neither significant difference in the number of trials to acquisition in the IA nor the number of baited food arms in RAM tasks between the groups. In the IA retrieval test, the time spent in the dark compartment in the donepezil-treated group was significantly less than the saline-treated group. Also, in the RAM retrieval test, the number of total memory and working memory errors of donepezil-treated rats was significantly less than that of the saline-treated ones.

Conclusion: The chronic administration of donepezil $(0.3 \mathrm{mg} / \mathrm{kg})$ had no significant effect on the learning process, but it can improve memory performance in normal rats.

\section{Introduction}

A cetylcholine is a widely distributed neurotransmitter in the central nervous system. It has a more modulatory function in the brain that is involved in learning and memory
[1]. The blockage of acetylcholine receptors with cholinergic drugs causes learning impairment [2-4]. Acetylcholinesterase (AChE) is one of the most fundamental enzymes in cholinergic synapses [5].

\section{* Corresponding Author:}

Siamak Shahidi, PhD.

Address: Neurophysiology Research Center, Hamadan University of Medical Sciences, Hamadan, Iran.

Tel: +98 (81) 38380208

E-mail:siamakshahidi@yahoo.com 
Alzheimer's disease is a progressive disorder caused by the lack of acetylcholine in the brain [6]. To date, AChE inhibitors such as donepezil hydrochloride prevent the reduction of acetylcholine in the brain in Alzheimer's disease $[7,8,9]$. Donepezil (Aricept) is an AChE inhibitor that is approved for the treatment of Alzheimer's disease with once-daily dosing $[9,10]$. The clinical efficacy of donepezil is based on the AChE inhibition that elevates the acetylcholine level at synapses and leads to the improvement of memory and learning impairments [11].

Donepezil in middle to high doses improved memory impairment in some tasks $[12,13]$. The AChE inhibitor enhances the survival of neurons in the hippocampus [14] and prevents the amyloid-beta peptide accumulation associated with neurotoxic $[15,16]$ and neuroprotective effects in transgenic mice $[17,18]$.

The high doses of donepezil have been used for the treatment of patients with Alzheimer's disease [19]. Using a low dose of donepezil reduces the side effects of the drug such as nausea, vomiting, diarrhea, and anorexia [9]. However, the chronic high doses of donepezil modulate cognitive behavior in the treatment of rats $[20,21]$. The prolonged exposure of donepezil at a low dose has not been clarified in the normal rats. Therefore, the aim of this study was to evaluate the effect of chronic administration of donepezil on learning and memory in the normal intact young rats.

\section{Materials and Methods}

\section{Animals}

Young male Wistar rats (Pasteur Institute, Tehran, Iran) weighing $140 \mathrm{~g}$ to $160 \mathrm{~g}$ were used. The animals had free access to food and water and were based in cages [ 4 rats in 1 cage) at $24 \pm 2^{\circ} \mathrm{C}$ under $12 / 12$ hours light-dark cycle (lights on at 7:00 am). All experiments were carried out during the light phase between 9:00 and 15:00. Two experimental groups consisted of 10 animals and were chosen randomly from different cages. All procedures for the treatment of the animals were approved by the research committee of the Hamadan University of Medical Sciences.

\section{Experimental Design and Drugs}

The animals were divided into the control and experimental groups ( $\mathrm{n}=10$ per each group). Donepezil $(0.3 \mathrm{mg} / \mathrm{kg}$, Sigma) was administered orally, using a gavage needle, to the experimental groups for 30 consecutive days. The control rats received saline in the same volume for 1 month.

\section{Inhibitory Avoidance Test}

The inhibitory avoidance apparatus and the procedure were basically the same as our previous studies [22-24]. Briefly, the apparatus consisted of 2 boxes of the same size $(20 \times 20 \times 30 \mathrm{~cm})$. There was a guillotine door in the middle of a dividing wall. The light-illuminated chamber was separated into a dark chamber with a guillotine door. The floors of both chambers were made of stainless steel rods $(3 \mathrm{~mm}$ in diameter and $10 \mathrm{~mm}$ apart) and spaced $1 \mathrm{~cm}$ apart. The floor of the dark compartment could deliver an electrified shock generator.

In the training phase, all animals were allowed to habituate in the apparatus. Each rat was gently placed in the white compartment and 5 seconds later, the guillotine door was raised and the animals were allowed to enter the dark module. Upon entering the dark compartment, the door was closed and after 30 seconds, the rats were removed from the dark compartment and put in their cage. This habituation trial was repeated 30 minutes later.

Then, the first acquisition trial started 30 minutes after the second habituation trial. The latency to enter the dark compartment (step-through latency during acquisition (STLa]) was recorded when the animal had placed all 4 paws in the dark compartment. During the acquisition, the guillotine door was closed and electric shocks $(50 \mathrm{~Hz}, 0.6$ $\mathrm{mA}$ intensity) were delivered to the grid floor of the dark compartment for 3 seconds immediately after the animal had entered the dark compartment [23]. The rat was removed from the apparatus and placed temporarily in its cage. Two minutes later, the animal was retested in the same way as in the previous trials. Then, 2 minutes later, the procedure was repeated. The rat received the same shock each time it reentered in the dark compartment with 4 paws in this chamber. The training was ended when the rat remained in the lighted chamber for 120 consecutive seconds. The number of trials to acquisition (entries into the dark chamber) was recorded.

A retention test was done 24 hours after the training phase. The rat was placed in the illuminated chamber, the guillotine door was raised 5 seconds later, and the latency of entering the dark compartment, the step-through latency during reacquisition (STLr), as well as the percentage of time spent in the dark compartment (TDC) were recorded in the absence of electric foot shocks during 5 minutes.

\section{Radial Arm Maze}

The rats were tested in an 8-arm radial maze. Apparatus and procedure were basically the same as our previous re- 
search [25]. The radial arm maze was made of wood and clear Plexiglas was elevated $10 \mathrm{~cm}$ from the floor with a central platform arena ( $20 \mathrm{~cm}$ in diameter). The apparatus consisted of 1 central compartment and 8 arms radiated from it at equal intervals. The center arena is surrounded by high clear Plexiglas guillotine doors and extends to the 8 arms ( $50 \mathrm{~cm}$ long, $15 \mathrm{~cm}$ high, and $10 \mathrm{~cm}$ wide). Plexiglas walls are at the sides and on the top of each arm. There was a cup at the end of each arm filled with food pellets. During the acquisition, 4 arms of the maze $[1,4,5,7]$ were baited randomly with the food. In the radial maze, to improve exploratory behavior required to obtain diets, the animals were food-restricted to reduce and maintain their weight at $85 \%$ of baseline weight.

In each trial, the rat was placed into the central compartment (start position) closed off by the door. After $15 \mathrm{sec}$ onds, to navigate the central compartment, the guillotine door was raised and they were allowed to find the food pellets in arms until all 4 pellets arms would be eaten or after 5 minutes. Four trials were taught to all rats per day for 18 consecutive days. The interval between trials was 5 minutes. In the acquisition phase, trial termination time and the number of baited food arms were recorded. One week after learning the trial, the retention test was performed. The number of memory errors was calculated. The number of entries into never-baited arms was regarded as referenced memory errors, while the number of re-entries into the arms, where the pellet had already been eaten, was regarded as working memory errors.

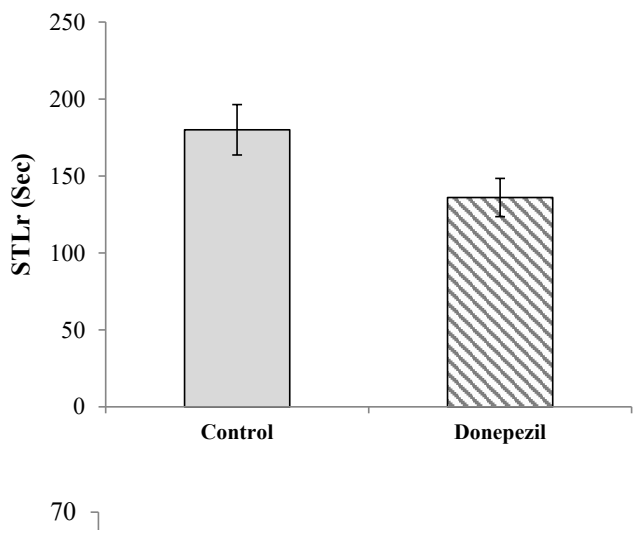

\section{Statistical Analysis}

The statistical analysis of data was performed by the Student t-test. $\mathrm{P}<0.05$ was considered significant. The data were expressed as Mean $\pm S D$ error of the Mean $\pm S E M$.

\section{Results}

\section{Inhibitory Avoidance Test}

In the acquisition trial, there was no difference between the control and experimental groups in the STLa and the number of trials to acquisition. The data for STLa and the number of trials were not shown.

The effect of 30-days treatment of donepezil on the percentage of TDC after the first stepping in the retention trial, which was carried out 24 hours after the acquisition of the inhibitory avoidance learning task in the control and experimental groups. The Student t test showed significant differences in the percentage of TDC after the first stepping between the groups $\left(T_{[18]}=51.53\right.$, $P<0.05$; Figure $1 B$ ). In the retention test ( 24 hours after training), the STLr of the donepezil-treated group was similar to the control rats (Figure 1A).

\section{Radial Arm Maze}

There were statistically significant differences between the experimental and control groups in acquisition trials. On the first day of training, the donepezil-receiving rats showed greater ability compared to the control group in the number of baited food arms $\left(T_{[18]}=15.78\right.$, $\mathrm{P}<0.05$; Figure 2). During the next days, no significant difference was observed between the two groups in the mentioned variable.

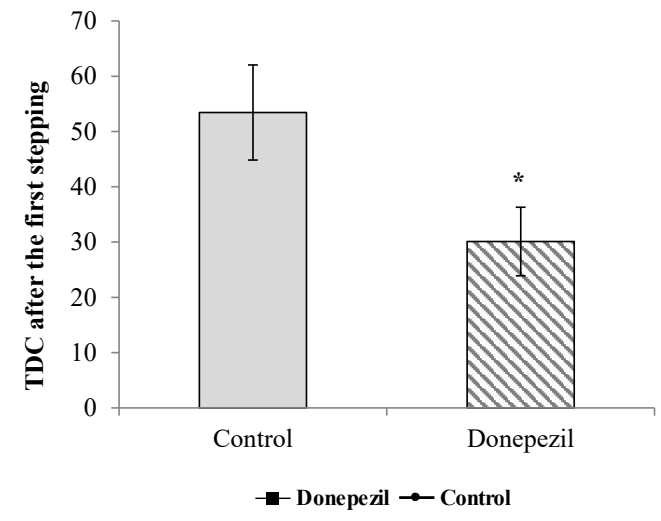

Figure 1. Effects of chronic supplementation of donepezil administration on the IAL

A. The step-through latency in the retention test; and B. The time spent in the dark compartment in the retention test after first stepping (B).

*P $<0.05$ compared to the control group. Each column and bar represents the Mean \pm SEM. 


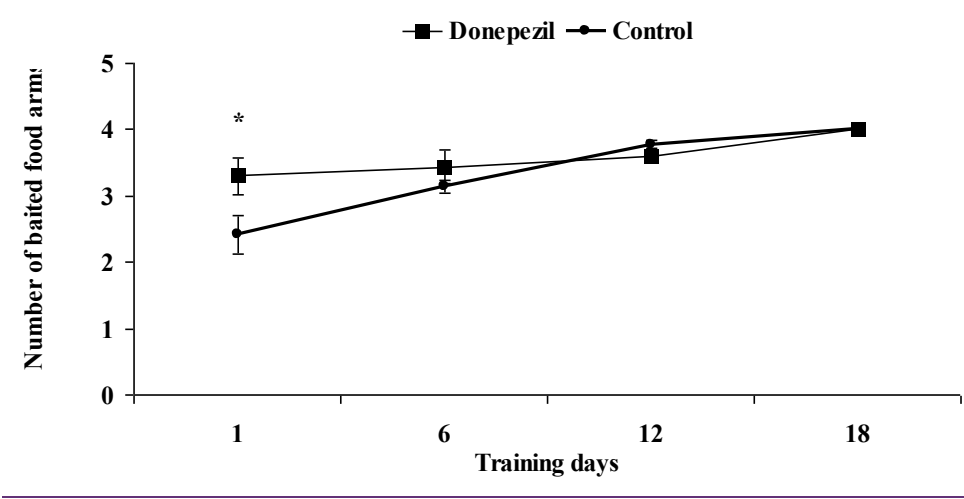

Figure 2. The effects of donepezil administration on the number of baited food arms

${ }^{*} \mathrm{P}<0.05$ compared to the control group. Each column and bar represents the Mean $\pm S E M$.

In the test day, the statistical analysis revealed no significant differences in the number of baited food arms and trial termination times between the groups. The Student $\mathrm{t}$ test showed that donepezil caused a significant decrease in the number of total memory errors in the test trial $\left(\mathrm{T}_{[18]}=3.72, \mathrm{P}<0.05\right.$; Figure $\left.3 \mathrm{~A}\right)$. On the other hand, the number of working memory errors in the experimental group was significantly fewer than that of the control group $\left(\mathrm{T}_{[18]}=6.92, \mathrm{P}<0.001\right.$; Figure $\left.3 \mathrm{~B}\right)$. However, there was no statistically significant difference between the experimental and control groups in the number of referenced memory errors in the test day.

\section{Discussion}

Donepezil $(0.3 \mathrm{mg} / \mathrm{kg})$ potentiated avoidance memory after 30 days of treatment; it improved learning on the first day and did not change it in the next days. Donepezil improved memory via decreasing the errors of working memory and decreasing the referenced memory errors.

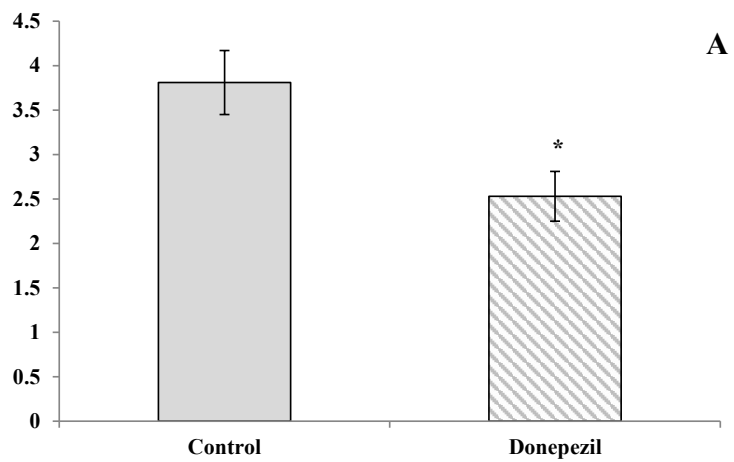

The current result is associated with previous studies reporting that the memory potentiation effect of donepezil is because of the inhibition of AChE, which increases the amount of acetylcholine released in the cholinergic terminals during learning memory. AChE inhibitors enhance the acetylcholine level in neural structures such as the hippocampus $[12,13,26]$. The chronic administration of donepezil ameliorated memory functions and explorative strategies in healthy young rats [21]. This study confirmed that the daily consumption of donepezil reduced recognition impairment, improved verbal encoding, and facilitated dependent memory consolidation in healthy young and older individuals [27-29]. The acute effect of donepezil reinforced spatial memory in healthy young volunteers [30].

Donepezil did not affect learning in healthy young rats. Donepezil improves learning and memory in memory deficit conditions. Donepezil ameliorated scopolamineinduced memory deficits in young and aged mice [13, 31] and prevented isoflurane-induced spatial memory

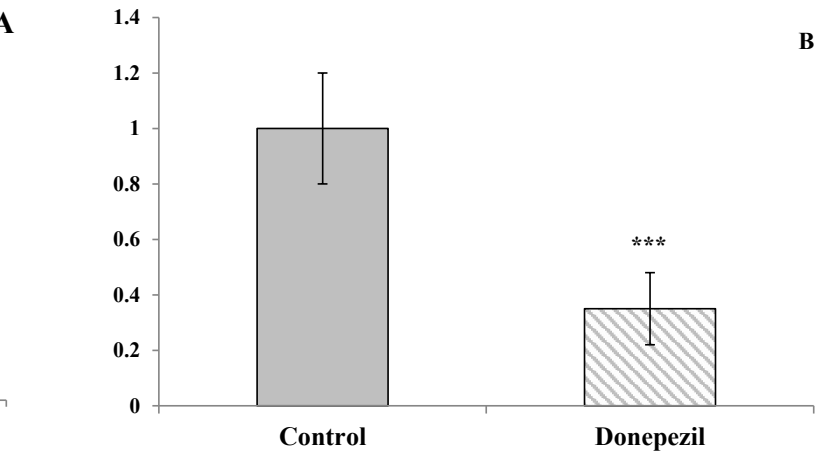

AJNPP

Figure 3. Effects of chronic supplementation of donepezil administration on the radial arm maze

A. The number of total memory errors; and $\mathrm{B}$. The number of working memory errors. ${ }^{*} \mathrm{P}<0.05,{ }^{* * *} \mathrm{P}<0.001$ compared to the control group. Each column and bar represents the Mean \pm SEM. 
impairment [26]. It is well demonstrated that the cholinergic system plays an important role in memory function. Donepezil has a protective effect against neuronal death [32-35]. It stimulated the regulation of acetylcholine receptors [12] and enhanced hippocampal neurogenesis and choline acetyltransferase [14]. The neuroprotective effects of donepezil exist in wild animals [15, $16]$ and transgenic mice $[17,18]$.

Donepezil did not affect learning in intact animals following chronic treatment. Three-week administration of donepezil $(10 \mathrm{mg} / \mathrm{kg}$ ) had no learning effect in the Morris water maze task in healthy animals [12]. Another study shows that healthy older subjects exhibited negative cognitive and neurophysiological responses to donepezil treatment [20]. The contradictory study indicated that donepezil injection accelerated acquisition and memory functions in intact adult rats following a 7-week treatment [21].

Learning and memory have different and complex mechanisms. Many proteins, neurotransmitters, and receptors are involved in learning and memory. One of the main systems is N-Methyl-D-aspartate (NMDA) receptor, which enhances learning and memory [37]. The anticholinesterase activity of donepezil is specific for the AChE enzyme at the cholinergic system and does not impress NMDA and other receptors in the brain [38]. Donepezil has been used in combination with the NMDA receptor antagonist for the treatment of patients with Alzheimer's disease [39]. That is the reason why donepezil improved memory without any restoring effects on learning in the present study.

The chronic treatment of donepezil reinforced avoidance and working memory and did not change reference memory in healthy rats. Further studies are necessary to evaluate the role of donepezil in learning processing in healthy animals.

\section{Ethical Considerations}

\section{Compliance with ethical guidelines}

All experimental procedures and examination conditions were approved by the Committee of Hamadan University of Medical Sciences and performed according to the Guide for Care and Use of Laboratory Animals published by the United States National Institutes of Health.

\section{Funding}

This work was supported by a Grant from Hamadan University of Medical Sciences.

\section{Authors' contributions}

Study concept and design, analysis and interpretation of data, and critical revision of the manuscript for important intellectual content: Nasrin Hashemi-Firouzi, Ali Ghaleiha, Alireza Komaki, and Siamak Shahidi; Acquisition of data, statistical analysis, and drafting of the manuscript: Nasrin Hashemi-Firouzi, and Siamak Shahidi; Administrative, technical, and material support: Siamak Shahidi and Alireza Komaki; study supervision: Siamak Shahidi.

\section{Conflict of interest}

The authors declare that there is no conflict of interest.

\section{References}

[1] Reis HJ, Guatimosim C, Paquet M, Santos M, Ribeiro FM, Kummer A, et al. Neuro-transmitters in the central nervous system \& their implication in learning and memory processes. Current Medicinal Chemistry. 2009; 16(7):796-840. [DOI:10.2174/092986709787549 271] [PMID]

[2] Rasmusson D, Dudar J. Effect of scopolamine on maze learning performance in humans. Experientia. 1979; 35(8):1069-70. [DOI:10.1007/BF01949946] [PMID]

[3] Ogura H, Aigner TG. MK-801 impairs recognition memory in rhesus monkeys: Comparison with cholinergic drugs. Journal of Pharmacology and Experimental Therapeutics. 1993; 266(1):60-4.

[4] Drachman DA, Leavitt J. Human memory and the cholinergic system: A relationship to aging? Archives of neurology. 1974 30(2):113. [DOI:10.1001/archneur.1974.00490320001001] [PMID]

[5] Gorfe AA, Lu B, Yu Z, McCammon JA. Enzymatic activity versus structural dynamics: The case of acetylcholinesterase tetramer. Biophysical Journal. 2009; 97(3):897-905. [DOI:10.1016/j.bpj.2009.05.033] [PMID] [PMCID]

[6] Kar S, Slowikowski SP, Westaway D, Mount HT. Interactions between [beta]-amyloid and central cholinergic neurons: Implications for Alzheimer's disease. Journal of Psychiatry \& Neuroscience. 2004; 29(6):427

[7] Terry AV, Buccafusco JJ. The cholinergic hypothesis of age and Alz heimer's disease-related cognitive deficits: Recent challenges and their implications for novel drug development. Journal of Pharmacology and Experimental Therapeutics. 2003; 306(3):821-7. [DOI:10.1124/jpet.102.041616] [PMID]

[8] Francis PT, Palmer AM, Snape M, Wilcock GK. The cholinergic hypothesis of Alzheimer's disease: A review of progress. Journal of Neurology, Neurosurgery \& Psychiatry. 1999; 66(2):137-47. [DOI:10.1136/jnnp.66.2.137] [PMID] [PMCID]

[9] Nguyen M, Salbu R. Donepezil 23 mg: A brief insight on efficacy and safety concerns. The Consultant Pharmacist ${ }^{\circledR}$. 2013; 28(12):800-3. [DOI:10.4140/TCP.n.2013.800] [PMID] 
[10] Whitehead A, Perdomo C, Pratt RD, Birks J, Wilcock GK, Evans JG. Donepezil for the symptomatic treatment of patients with mild to moderate Alzheimer's disease: A meta-analysis of individual patient data from randomised controlled trials. International journa of geriatric psychiatry. 2004; 19(7):624-33. [DOI:10.1002/gps.1133] [PMID]

[11] Akasofu S, Kimura M, Kosasa T, Ogura H, Sawada K. Protective effect of donepezil in primary-cultured rat cortical neurons exposed to $\mathrm{N}$-methyl-d-aspartate (NMDA) toxicity. European Journal of Pharmacology. 2006; 530(3):215-22. [DOI:10.1016/j. ejphar.2005.11.057] [PMID]

[12] Kwon KJ, Kim MK, Lee EJ, Kim JN, Choi B-R, Kim SY, et al. Effects of donepezil, an acetylcholinesterase inhibitor, on neurogenesis in a rat model of vascular dementia. Journal of the Neurological Sciences. 2014; 347(1):66-77. [DOI:10.1016/j.jns.2014.09.021] [PMID]

[13] Hashimoto T, Hatayama Y, Nakamichi K, Yoshida N. Procognitive effect of AC-3933 in aged mice, and synergistic effect of combination with donepezil in scopolamine-treated mice. European Journal of Pharmacology. 2014; 745:123-8. [DOI:10.1016/j. ejphar.2014.10.015] [PMID]

[14] Kotani S, Yamauchi T, Teramoto T, Ogura H. Donepezil, an acetylcholinesterase inhibitor, enhances adult hippocampal neurogenesis. Chemico-Biological Interactions. 2008; 175(1):227-30. [DOI:10.1016/j.cbi.2008.04.004] [PMID]

[15] Tang S-S, Hong H, Chen L, Mei Z-I, Ji M-j, Xiang G-q, et al. Involvement of cysteinyl leukotriene receptor 1 in $A \beta$ 1-42-induced neurotoxicity in vitro and in vivo. Neurobiology of Aging. 2014; 35(3):5909. [DOI:10.1016/j.neurobiolaging.2013.09.036] [PMID]

[16] Noh MY, Koh SH, Kim Y, Kim HY, Cho GW, Kim SH. Neuroprotective effects of donepezil through inhibition of GSK-3 activity in amyloid- $\beta$-induced neuronal cell death. Journal of neurochemistry. 2009;108(5):1116-25. [DOI:10.1111/j.1471-4159.2008.05837.x] [PMID]

[17] Ye CY, Lei Y, Tang XC, Zhang HY. Donepezil attenuates A $\beta$-associated mitochondrial dysfunction and reduces mitochondrial $A \beta$ accumulation in vivo and in vitro. Neuropharmacology. 2015; 95:29-36. [DOI:10.1016/j.neuropharm.2015.02.020] [PMID]

[18] Romberg C, Mattson MP, Mughal MR, Bussey TJ, Saksida LM. Impaired attention in the 3xTgAD mouse model of Alzheimer's disease: Rescue by donepezil (Aricept). The Journal of Neuroscience. 2011; 31(9):3500-7. [DOI:10.1523/JNEUROSCI.5242-10.2011] [PMID] [PMCID]

[19] Geldmacher DS. Donepezil (Aricept ${ }^{\circledast}$ ) for treatment of Alzheimer $s$ disease and other dementing conditions. Expert Review of Neurotherapeutics. 2004; 4(1):5-16. [DOI:10.1586/14737175.4.1.5] [PMID]

[20] Balsters JH, O'Connell RG, Martin MP, Galli A, Cassidy SM, Kilcullen $\mathrm{SM}$, et al. Donepezil impairs memory in healthy older subjects: Behavioural, EEG and simultaneous EEG/fMRI biomarkers. PIOS ONE. 2011; 6(9):e24126. [DOI:10.1371/journal.pone.0024126] [PMID] [PMCID]

[21] Cutuli D, Foti F, Mandolesi L, De Bartolo P, Gelfo F, Federico F, et al. Cognitive performance of healthy young rats following chronic donepezil administration. Psychopharmacology. 2008; 197(4):66173. [DOI:10.1007/s00213-008-1084-0] [PMID]

[22] Hasanein P, Shahidi S. Preventive effect of Teucrium polium on learning and memory deficits in diabetic rats. Medical science monitor: International medical journal of experimental and clinica research. 2012; 18(1):Br41-6. [DOI:10.12659/MSM.882201] [PMID] [PMCID]

[23] Mahmoodi M, Shahidi S, Hasanein P. Involvement of the ventral tegmental area in the inhibitory avoidance memory in rats. Physiology \& Behavior. 2011; 102(5):542-7. [DOI:10.1016/j.physbeh.2011.01.011] [PMID]

[24] Jabbarpour Z, Shahidi S, Saidijam M, Sarihi A, Hassanzadeh T, Esmaeili R. Effect of tempol on the passive avoidance and novel object recognition task in diabetic rats. Brain Research Bulletin. 2014 101:51-6. [DOI:10.1016/j.brainresbull.2013.12.013] [PMID]

[25] Shahidi S, Arjipour M, Komaki A, Mahmoodi M. Differential Effects of Sildenafil (Viagra) on Processing Steps of Spatial Learning and Memory in Rat. Avicenna Journal of Neuro Psych Physiology. 2014; 1(1). [DOI:10.17795/ajnpp-18671]

[26] Su D, Zhao Y, Wang B, Xu H, Li W, Chen J, et al. Isoflurane-Induced Spatial Memory Impairment in Mice is Prevented by the Acetylcholinesterase Inhibitor. PLoS One. 2011; 6(11):e27632. [DOI:10.1371/ journal.pone.0027632] [PMID] [PMCID]

[27] Hornung OP, Regen F, Dorn H, Anghelescu I, Kathmann N, Schredl $M$, et al. The effects of donepezil on postlearning sleep EEG of healthy older adults. Pharmacopsychiatry. 2009; 42(1):9-13. [DOI:10.1055/s-0028-1083820] [PMID]

[28] Chuah LY, Chong DL, Chen AK, Rekshan WR, 3rd, Tan JC, Zheng H, et al. Donepezil improves episodic memory in young individuals vulnerable to the effects of sleep deprivation. Sleep. 2009; 32(8):999 1010. [DOI:10.1093/sleep/32.8.999] [PMID] [PMCID]

[29] FitzGerald DB, Crucian GP, Mielke JB, Shenal BV, Burks D, Womack $K B$, et al. Effects of donepezil on verbal memory after semantic processing in healthy older adults. Cognitive and behavioral neurology: Official Journal of the Society for Behavioral and Cognitive Neurology. 2008; 21(2):57-64. [DOI:10.1097/WNN.0b013e3181799df1] [PMID]

[30] Zaninotto AL, Bueno OF, Pradella-Hallinan M, Tufik S, Rusted J, Stough C, et al. Acute cognitive effects of donepezil in young, healthy volunteers. Human psychopharmacology. 2009; 24(6):45364. [DOI:10.1002/hup.1044] [PMID]

[31] Tiseo PJ, Foley K, Friedhoff LT. The effect of multiple doses of donepezil $\mathrm{HCl}$ on the pharmacokinetic and pharmacodynamic profile of warfarin. British Journal of Clinical Pharmacology. 1998; 46(Suppl 1):45-50. [DOI:10.1046/j.1365-2125.1998.0460s1045.x] [PMID] [PMCID]

[32] Takada Y, Yonezawa A, Kume T, Katsuki H, Kaneko S, Sugimoto $H_{\text {, }}$ et al. Nicotinic acetylcholine receptor-mediated neuroprotection by donepezil against glutamate neurotoxicity in rat cortical neurons. Journal of Pharmacology and Experimental Therapeutics. 2003; 306(2):772-7. [DOI:10.1124/jpet.103.050104] [PMID]

[33] Shen H, Kihara T, Hongo H, Wu X, Kem W, Shimohama S, et al. Neuroprotection by donepezil against glutamate excitotoxicity involves stimulation of $\alpha 7$ nicotinic receptors and internalization of NMDA receptors. British Journal of Pharmacology. 2010; 161(1):127-39. [DOI:10.1111/j.1476-5381.2010.00894.x] [PMID] [PMCID]

[34] Noh MY, Koh SH, Kim SM, Maurice T, Ku SK, Kim SH. Neuroprotective effects of donepezil against $A \beta 42$-induced neuronal toxicity are mediated through not only enhancing PP2A activity but also regulating GSK-3 $\beta$ and nAChRs activity. Journal of Neurochemistry. 2013 127(4):562-74. [DOI:10.1111/jnc.12319] [PMID]

[35] Leyhe T, Hoffmann N, Stransky E, Laske C. Increase of SCF plasma concentration during donepezil treatment of patients with early 
Alzheimer's disease. International Journal of Neuropsychopharmacology. 2009; 12(10):1319-26. [DOI:10.1017/S1461145709990216] [PMID]

[36] Tang Y-P, Shimizu E, Dube GR, Rampon C, Kerchner GA, Zhuo M, et al. Genetic enhancement of learning and memory in mice. Nature. 1999; 401(6748):63. [DOI:10.1038/43432] [PMID]

[37] Kumar A, Sharma S. Donepezil. StatPearls. Treasure Island (FL): StatPearls Publishing StatPearls Publishing LLC.; 2019.

[38] Knapp M, King D, Romeo R, Adams J, Baldwin A, Ballard C, et al Cost-effectiveness of donepezil and memantine in moderate to severe Alzheimer's disease (the DOMINO-AD trial). International Journal of Geriatric Psychiatry. 2017; 32(12):1205-16. [DOI:10.1002/ gps.4583] [PMID] [PMCID] 
